\title{
Debonding Performance of CFRP-Strengthened Nanomaterial Concrete Beam Using Wavelet Packet Analysis
}

\author{
Yang Liu, ${ }^{1,2}$ Ming Zhang, ${ }^{1}$ Xinfeng Yin $\mathbb{D}^{1},{ }^{1}$ Zhou Huang, ${ }^{1}$ and Lei Wang ${ }^{1}$ \\ ${ }^{1}$ School of Civil Engineering, Changsha University of Science and Technology, Changsha 410114, China \\ ${ }^{2}$ School of Civil Engineering, Hunan University of Technology, Zhuzhou 412007, China \\ Correspondence should be addressed to Xinfeng Yin; yinxinfeng@163.com
}

Received 17 December 2019; Revised 23 February 2020; Accepted 27 March 2020; Published 25 April 2020

Academic Editor: Stefano Stassi

Copyright ( 2020 Yang Liu et al. This is an open access article distributed under the Creative Commons Attribution License, which permits unrestricted use, distribution, and reproduction in any medium, provided the original work is properly cited.

\begin{abstract}
The carbon fiber reinforced polymer- (CFRP-) strengthened nanomaterial concrete beam (SNCB) has been increasingly attracting a widespread attention because of the advantages of using the excellent properties of nanomaterials to improve structural properties. An active sensing approach based on a piezoceramic transducer is developed to detect the interfacial debonding performance of CFRP-SNCB. A CFRP-SNCB specimen was fabricated and subjected to periodic loading test to initiate the debonding damage. Three piezoceramic smart aggregates (SAs) and three piezoceramic smart nanomaterial aggregates (SNAs) are embedded in the specimen and used as an actuator and sensor. Experiments show that the nanomaterial concrete becomes a good conduit for wave propagation due to the nucleation and filling effect of nanomaterial. The stress wave signal caused by the embedded SNAs is more sensitive to the debonding performance between CFRP and concrete than SA. The attenuation of stress wave caused by the increase of the severity of debonding damage can be clearly observed from the signals received from SAs and SNAs in the frequency domain analysis. The debonding cracking of the tension end region is earlier than the bond end region, which proves the starting point of structural debonding damage. Furthermore, the debonding state can be evaluated by wavelet packet analysis. The research results demonstrate that the proposed method has potentials to detect the interfacial debonding performance of CFRP-SNCB.
\end{abstract}

\section{Introduction}

Prestressed carbon fiber reinforced polymer- (CFRP-) strengthened nanomaterial concrete beam (SNCB) is a new and efficient reinforcement, repair, and transformation technology. CFRP plate has the advantages of remedying the defects of traditional materials, such as light weight, high tensile strength, high corrosion resistance, good fatigue endurance, and nonelectromagnetic properties $[1,2]$. On the other hand, it is well known that nanomaterials can significantly improve the performance of concrete using the cement-based materials in view of their physical effect [3]. Therefore, nanomaterial concrete structure with nearsurface mounted (NSM) prestressed CFRP plates has attracted more and more attention in civil engineering [4]. The bonding area between CFRP and concrete is increased by the NSM process to obtain better CFRP-concrete bonding properties. However, the improvement of bearing capacity depends on the integrity of CFRP-concrete interface. The end of the CFRP plates is prone to stress concentration, which may lead to the appearance of microcracks in the early stage. Debonding failure initially occurs at very small cracks and then propagates to other parts of the structure. Debonding cracks in the internal interface of the structure are difficult to observe in the engineering. Once the cracks are connected to each other, the bearing capacity of the structure will immediately fail, which may eventually cause huge loss of life and property. Therefore, in order to solve this problem, the materials of nanomaterial-based concrete are introduced in the structures, and thus, the interface debonding performance of CFRP-SNCB is investigated in this study. Simultaneously, it is desirable to develop a reliable monitoring system to monitor the initial installation quality and the long-term efficiency of the CFRP tension zone [5].

The interface of CFRP-SNCB is formed by bonding concrete and CFRP plate using epoxy resin. In order to fully 
utilize the properties of the CFRP material, the CFRP is tensioned and embedded in the concrete, resulting in a complex stress condition at the CFRP end. It is easy to cause brittle failure due to dynamic loads caused by moving vehicles [6], corrosions [7], or impact loading [8] during extreme events. With the development of society, the requirements of civil engineering for concrete performance are higher and higher, but the defects of concrete restrict the service in some fields. At present, one of the means to improve the performance of concrete is the composite of materials, such as materials with microscopic dimensions (such as nano- $\mathrm{CaCO}_{3}$ and nano$\mathrm{SiO}_{2}$ ) mixed into concrete to improve the performance. Nano- $\mathrm{CaCO}_{3}$ has become one of the common materials in the research of composite concrete materials because of its low price and improvement of concrete properties. The physical and mechanical properties of concrete can be improved by mixing nano- $\mathrm{CaCO}_{3}$ into concrete. The application of nano- $\mathrm{CaCO}_{3}$ has become a common method to improve the performance of concrete materials in order to better serve civil engineering [9]. The concrete materials show less porous and more uniform characteristics because of the excellent nucleation and filling effect of nano- $\mathrm{CaCO}_{3}$. The crack initiation can be reduced by producing denser microstructure to improve the performance. In addition, nano- $\mathrm{CaCO}_{3}$ is inexpensive because of the large supply of $\mathrm{CaCO}_{3}$ in nature and the prototype of nano- $\mathrm{CaCO}_{3}$ has been employed in concrete [10-12]. Therefore, the application of nano- $\mathrm{CaCO}_{3}$ in cement-based composites has received extensive attention in recent years. The interface performance of CFRP-SNCB can provide significant enhancement by using the cementbased material.

It is urgent to find an effective method to identify the debonding damage between CFRP and concrete [13]. Traditional detection methods have some defects that do not meet the needs of current development. In addition, the damage of the structure cannot be judged directly by the collected data. Therefore, the prospect of real-time and in-service monitoring is limited. The emergence of intelligent materials provides an effective way for engineering structural health monitoring technology [14]. The application of intelligent piezoceramic materials in structural health monitoring provides a new idea for the development of a new sensor with sensitive sensing, safe, and reliable and wide measurement range. Song et al. proposed the concept of smart aggregates (SAs), which combines concrete with piezoceramic Lead Zirconate Titanate (PZT) [15-17]. Jiang et al. monitored crack damage of FRP-reinforced concrete beams by SAs and successfully provided early warning [18]. The SAs are embedded in the concrete structure as a transducer [19]. However, piezoceramic SAs generate stress wave energy, which requires medium propagation. The presence of higher porosity in the interior of the concrete structure consumes the energy of propagation. The advantages based on the filling and nucleation effects of nanomaterials and the characteristics of piezoceramic materials are combined to reduce energy dissipation and increase sensitivity.

The interface bonding connection of CFRP-SNCB was studied by using an active sensing approach in the loading progression. The CFRP-SNCB in the experimental program was made of concrete, CFRP plate, epoxy resin, $2 \mathrm{wt} \%$ nano- $\mathrm{CaCO}_{3}$, longitudinal distributed reinforcement, steel stirrups, and SAs and piezoceramic smart nanomaterial aggregates (SNAs). The loading test of the CFRP-SNCB embedded SAs and SNAs was carried out. The signals received by the SA and SNA sensors are analyzed in frequency domain. The wavelet packet energy distribution of SA and SNA measurement in different frequency bands is studied, and the wavelet packet analysis is proposed to evaluate the damage state. At the same time, the feasibility and superiority of the approach were verified by comparing with the deflection change and strain data of the beam.

\section{Experimental Methods}

2.1. Nanomaterials. Nanomaterials have some special properties such as high surface activity and strong oxidation because of its small particle size and large specific surface area. Due to the large rigidity and small flexibility of concrete, cracks often occur in the process of service, causing structural damage. The physical and mechanical properties of concrete can be improved by mixing nanomaterials into concrete. Nano- $\mathrm{CaCO}_{3}$ can improve bending strength and flexural modulus of concrete. Nano- $\mathrm{CaCO}_{3}$ material with a size range of $50-100 \mathrm{~nm}$ was used in this experiment. Nanoparticles have a tendency to agglomerate in concrete with high concentration of nano- $\mathrm{CaCO}_{3}$, resulting in higher particle sizes $[20,21]$. The tendency of nanoparticle agglomeration reduces the ability to act as an effective filler in concrete $[22,23]$. Lower concentrations of nano- $\mathrm{CaCO}_{3}$ provide a denser microstructure and hydrated product formation than other nanoadditives, contributing to early strength and durability. Therefore, the concentration of nanomaterials should not be taken too high. In this experiment, nano- $\mathrm{CaCO}_{3}$ with $2 \%$ concentration was used to exhibit nucleation and filling effects and more homogeneous structure.

2.2. Smart Aggregates. Piezoelectric material refers to the material with the property of piezoelectric effect. Due to the special principle of piezoelectric materials, it can be divided into positive and inverse piezoelectric effects [24]. According to the principle of positive piezoelectric effect, the piezoelectric material can be made into a signal sensing receiving device. The piezoelectric material can be made into a signal transmitting driving device by using the inverse piezoelectric effect. In the experimental study, the signal propagates in the form of a longitudinal wave. In order to consider the convenience of fabrication, this paper selects the piezoceramic patch of the PZT-5A model with both anode and cathode on the same side. The selected PZT patches have excellent stretching vibration function for the accuracy of the test. The size of PZT patch is $15 \mathrm{~mm} \times 10 \mathrm{~mm} \times 0.3 \mathrm{~mm}$. In this research, the PZT patches with the mode of $d_{33}$ (compression type) were employed, as shown in Figure 1.

Due to the brittle and fragile nature of the piezoceramic PZT patch, it cannot be directly buried in the concrete structure. In order to solve this problem, Song et al. proposed the concept of smart aggregates (SAs) [15]. SA is mainly made of concrete block, wire, Bayonet Neill-Concelman (BNC) 


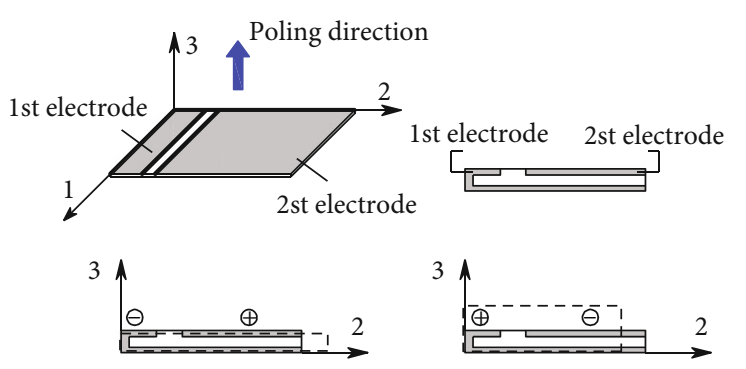

(a)

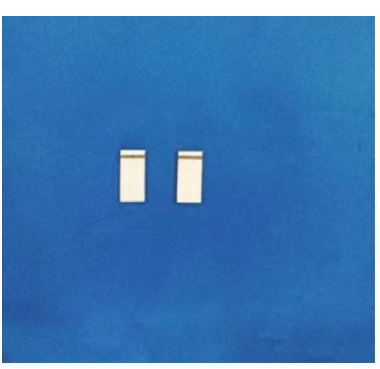

(b)

FIgure 1: (a) Principle diagram of the PZT patch; (b) a photo of a PZT.

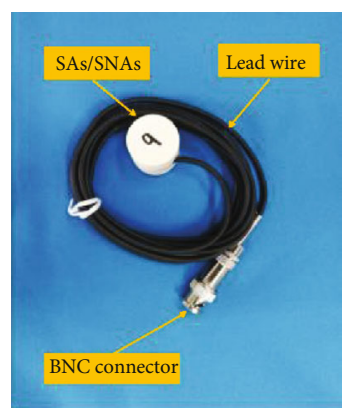

(a)

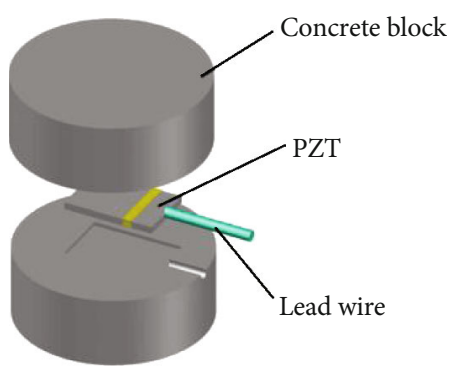

(b)

Figure 2: (a) A photo of a SA/SNA; (b) the schematic structure of the SA/SNA.

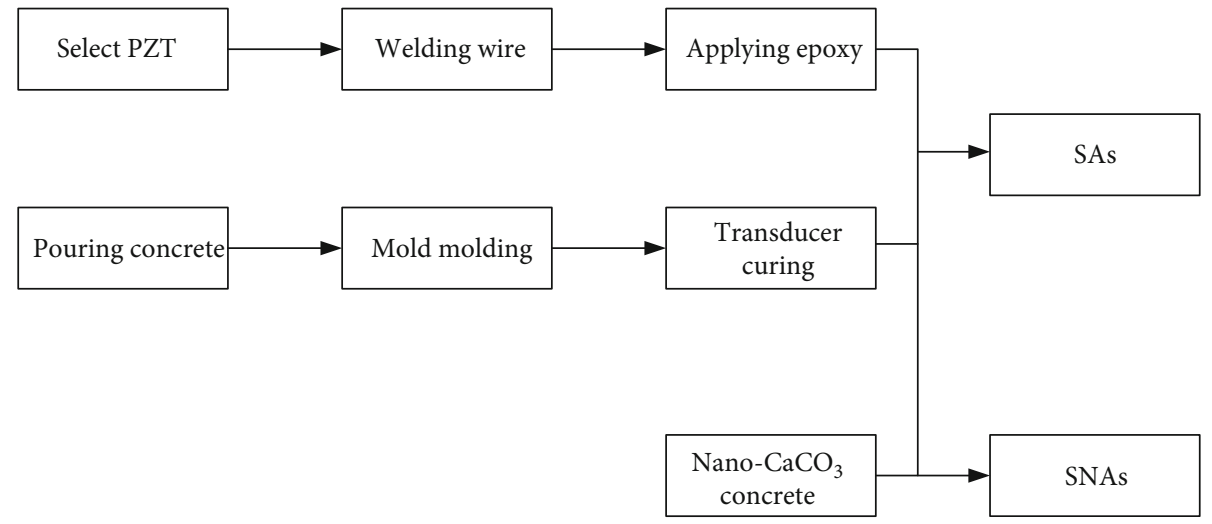

FIgURE 3: The production of SA and SNA.

connector, epoxy resin, and PZT patch. Epoxy resin not only plays the role of waterproof and bonding but also ensures the good performance of a PZT patch [25]. The SA is formed by embedding wire-connected PZT patch in premade small concrete blocks. The PZT patch is buried inside the concrete block, so that the influence of external environment such as temperature and humidity on the PZT patch is limited, and the concrete block has a protective effect on the PZT patch. Therefore, the prepared SA can be well combined with the concrete structure and has both an intelligent function and an aggregate function. For the connection, one end of the lead wire is soldered to the anode and cathode of the PZT patch and the other end is connected to the Bayonet
Neill-Concelman (BNC) connector [26]. The fabricated piezoelectric sensor is shown in Figure 2. However, nano- $\mathrm{CaCO}_{3}$ has nucleation and filling effects, which can reduce the loss of wave propagation energy. In order to improve the accuracy, $2 \%$ concentration of nano- $\mathrm{CaCO}_{3}$ was added to the precast concrete block to form the smart nanomaterial aggregates (SNAs). The SNAs are mainly made of nano- $\mathrm{CaCO}_{3}$ concrete block, wire, BNC connector, epoxy resin, and PZT patch. SA and SNA have the same PZT patch, manufacturing process, and size; the only difference is the precast concrete block. SNA's precast concrete blocks contain nano- $\mathrm{CaCO}_{3}$. The diameter of the SNA and SA is $25 \mathrm{~mm}$, and the height is $20 \mathrm{~mm}$. The production of SA and SNA is shown in Figure 3. 


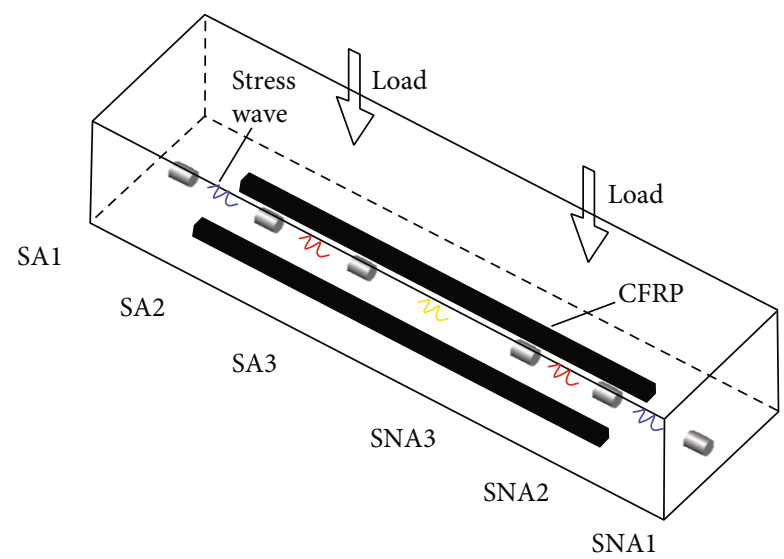

FIgURE 4: Three-dimensional diagram of specimen.

2.3. Principle. This paper introduces an active sensing approach based on a SA/SNA sensor to monitor the secure bonding state of the nanomaterial concrete beam with NSM prestressed CFRP plates. The three-dimensional diagram of the nanomaterial concrete beam with NSM prestressed CFRP plates is shown in Figure 4. Figure 5 shows the principle of the active sensing approach. Six piezoceramic SAs/SNAs were buried in the beam at predetermined position to detect the interface debonding performance, among which two SAs/SNAs were used as an actuator to excite stress waves and four SAs/SNAs were used as a sensor to receive stress wave response [27]. Loading tests were carried out to identify the debonding performance of the CFRP-SNCB. In the noload stage, the energy loss of the signal wave excited by the actuator is less in the transmission process, and the sensor can receive a strong stress wave signal energy as the basic signal, as shown in Figure 5(a). When loaded into the cracking stage, the crack first appeared on the lower edge of the CFRP-SNCB due to the stress change at the end of CFRP. At this point, the stress wave signal received by the SAs/SNAs will be reflected and attenuated, as shown in Figure 5(b). As the load continues further, the number and severity of cracks in the lower part of the beam will continuously cause debonding between CFRP and concrete. At this point, the structural adhesive and the concrete in the tension area withdraw from service. The tensile stress of the structure is mainly borne by the tensile reinforcements and CFRP plates, which will cause further attenuation of the signal received by the SA/SNA sensor, as shown in Figure 5(c). When debonding failure is caused by crack development, the signal received by the SA/SNA sensor will become very small, as shown in Figure 5(d).

2.4. Wavelet Packet-Based Active Sensing Method. The active sensing method is used to monitor the fracture damage development of CFRP-SNCB under different vertical load levels. The development of cracks in the concrete and the development of debonding damage at the interface between the concrete and the CFRP plates will cause changes in the collected stress waves. The change of amplitude, phase, and energy can reflect the attenuation of stress wave. Here, we only analyze the internal damage development of compo- nents by analyzing the change degree of signal amplitude and energy. Compared with the time-domain signal, the frequency domain signal is more intuitive in the change of signal amplitude, so we transform the time-domain data into the frequency domain signal through Fourier transform and carry out comparative analysis.

The formula for time-frequency domain conversion of the acquired signal by Fourier transform is shown in (1) [28].

$$
X(\omega)=\int_{-\infty}^{\infty} x(t) \exp (-i \omega t) d t
$$

where $X(\omega)$ is Fourier transformed by $x(t)$.

The time-frequency domain analysis method was mainly based on wavelet packet energy, which was calculated from the swept frequency signal. Because the signal energy is directly proportional to the second power of the signal amplitude, the structural damage is identified by comparing the difference between the energy of the received signals. In this paper's experimental research, the wavelet packet energy of the swept frequency signal is calculated, and the difference of the energy of the signals received by each sensor is compared and analyzed to identify the damage. The wavelet packet analysis is developed based on the orthogonal wavelet theory. This method can not only decompose low-frequency signals but also deeply decompose high-frequency signals. As the number of decomposition layers increases, the resolution is higher, and the decomposition has neither redundancy nor omission. A large number of medium- and high-frequency signals could be selected to determine the appropriate frequency band for the local time domain analysis. Hence, it is a promising application in structural damage detection. Therefore, this paper can analyze the signal by wavelet packet principle and form the damage index to identify the severity of structural damage.

$X$ represents the original monitoring signal. The principle of wavelet packet is used to decompose $X$ into multiple component signals of equal width band by $N$-level wavelet packets. In this paper, the original signal is decomposed by three layers of wavelet packet.

First, the voltage measurement signal $X_{k}$ of the SA/SNA sensor $k(k=1, \cdots, N)$ is decomposed by $N$-level wavelet packet decomposition into $2^{N}$ frequency bands as described in the following equation [29]:

$$
X_{k}=x_{k, 1}+x_{k, 2}+x_{k, i}+\cdots+x_{k, 2^{N}},
$$

where $X_{k}$ represents the original monitoring signal, $x_{k, i}$ is the signal after $N$-level wavelet packet decomposition, and $i$ is the frequency band index $\left(i=1 \cdots 2^{N}\right)$. In this study, $N=3$. The $x_{k, i}$ can be further expressed as follows [30]:

$$
x_{k, i}=\left[x_{k, i, 1}, x_{k, i, 2}, \cdots, x_{k, i, m}\right] \text {, }
$$

where $m$ is the number of sampling data. 


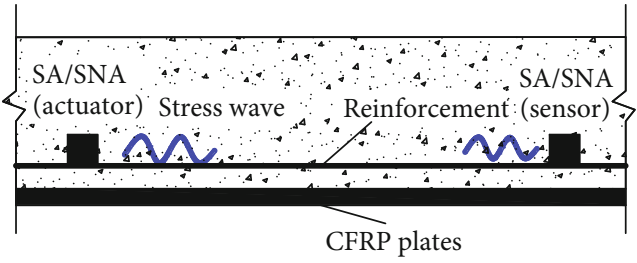

(a)

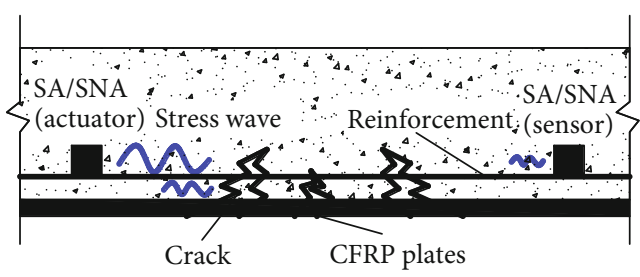

(c)

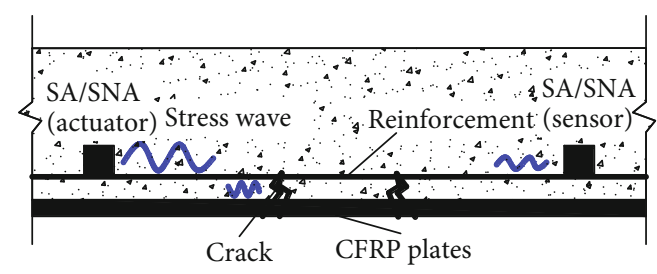

(b)

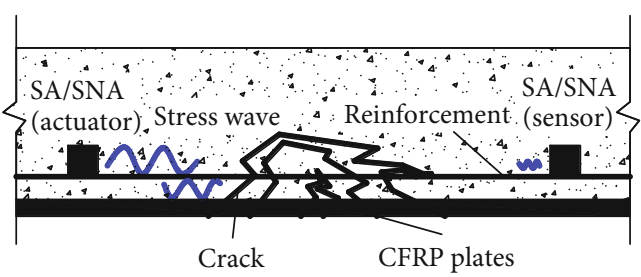

(d)

FIgURE 5: The principle diagram of the active sensing approach.

Then, the energy vector corresponding to the SA/SNA sensor $k$ can be defined as follows:

$$
\bar{E}_{k}=\left[e_{k, 1}, e_{k, 2}, e_{k, \mathrm{i}}, \cdots, e_{k, 2^{N}}\right]
$$

where $e_{k, i}$ is the corresponding energy of the wavelet decomposed signal and can be defined as follows [26]:

$$
e_{k, i}=\sum_{j=1}^{m} x_{k, i, j}{ }^{2}
$$

Accordingly, the energy corresponding to each SA/SNA sensor can be defined as the 2-norm of the above energy vector as follows:

$$
E_{k}=\sum_{i=1}^{2^{N}} e_{k, i}
$$

The energy of loading process is calculated based on wavelet packet theory, and the damage index is determined by root mean square deviation (RMSD) to evaluate the damage extent of the specimen [31].

$$
\operatorname{RMSD}_{k}=\sqrt{\frac{\sum_{i=1}^{2^{N}}\left(E_{k, i}-E_{1, i}\right)^{2}}{\sum_{i=1}^{2^{N}}\left(E_{1, i}\right)^{2}}},
$$

where $E_{1, i}$ represents the signal energy in the structural health state and $E_{k, i}$ represents the signal energy of the structural damage state ( $k$ loading phase).

In order to eliminate the initial error of different sensors, the damage index is normalized [32].

$$
I_{i}=\frac{\mathrm{RMSD}_{b}-\mathrm{RMSD}_{i}}{\mathrm{RMSD}_{b}-\mathrm{RMSD}_{t}},
$$

where $i$ denotes the $i$ th test condition in the experiment. The variable $\mathrm{RMSD}_{b}$ is the damage index when the structure is in the state of complete failure, and $\mathrm{RMSD}_{t}$ is the damage index when the structure is in the state of health.

The energy loss of stress wave propagation is caused by structural damage (such as cracking, debonding, and bond slip) at different loading stages. The structure is in the state of no debonding and cracking before the loading test, indicating that the damage index value is zero. The damage index reaches a certain value, indicating that the structure will exhibit debonding/cracking during the loading process [33]. When the damage index is closer to 1 , the structural state indicates that the damage extent is serious.

2.5. Specimen Fabrication. A specimen with a cross-section of $150 \mathrm{~mm} \times 250 \mathrm{~mm}$ and a length of $2700 \mathrm{~mm}$ was designed. The test specimens in the experimental program were made of concrete, CFRP plate, epoxy resin, longitudinal distributed reinforcement, steel stirrups, SAs, SNAs, and nano- $\mathrm{CaCO}_{3}$. The tensile area of the specimen is divided into prestressed CFRP-bonded section, nonprestressed CFRP-bonded section, and unbonded section. The boundary between the prestressed CFRP-bonded section and the nonprestressed CFRP-bonded section is called the tensioned end, and the junction of the nonprestressed CFRP-bonded section and the unbonded section is called the bonded end. The total bond length of CFRP plate in specimen is $1800 \mathrm{~mm}$, the length of prestressed bond section is $1400 \mathrm{~mm}$, and the length of nonprestressed bond section on both sides of beam is $200 \mathrm{~mm}$, as shown in Figures 6 and 7. Strain gauges were symmetrically arranged on the outside of the CFRP plate at the nonprestressed CFRP bond section of the beam to measure the strain of the CFRP plate during the loading process, as shown in Figure 6. The spacing of the strain gauges is $50 \mathrm{~mm}$. The cement used for casting the specimen is type 32.5 Portland cement [19]. The average compressive strength of the concrete for 28 days is $30 \mathrm{MPa}$. Specimen is mixed with $2 \mathrm{wt} \%$ nano- $\mathrm{CaCO}_{3}$ in concrete. The detailed mix design used in the casting of concrete specimens is given in Table 1. The tensile strength and modulus of the CFRP plate are $2068 \mathrm{MPa}$ and $140 \mathrm{GPa}$, respectively. The details of the CFRP plate are shown in Figure 7 . Epoxy resin adhesive is 


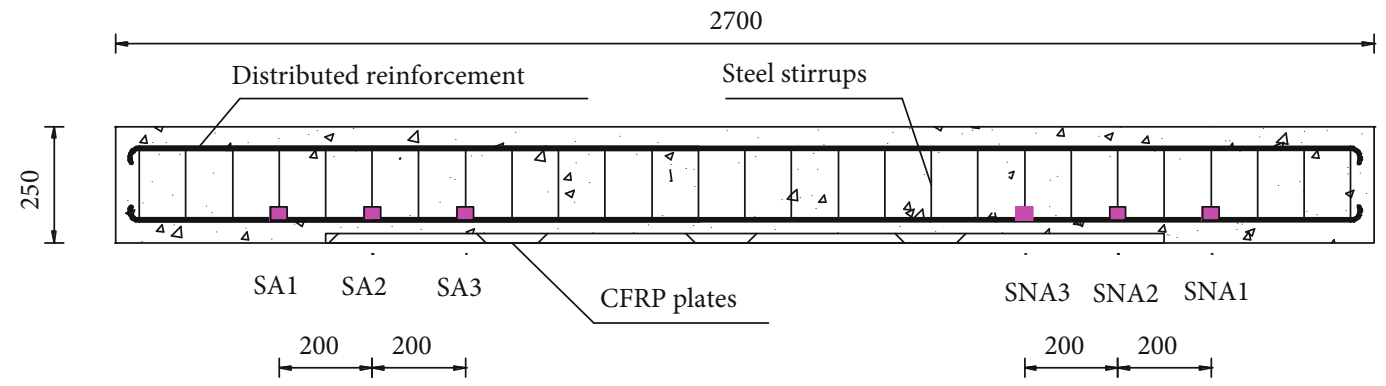

(a)

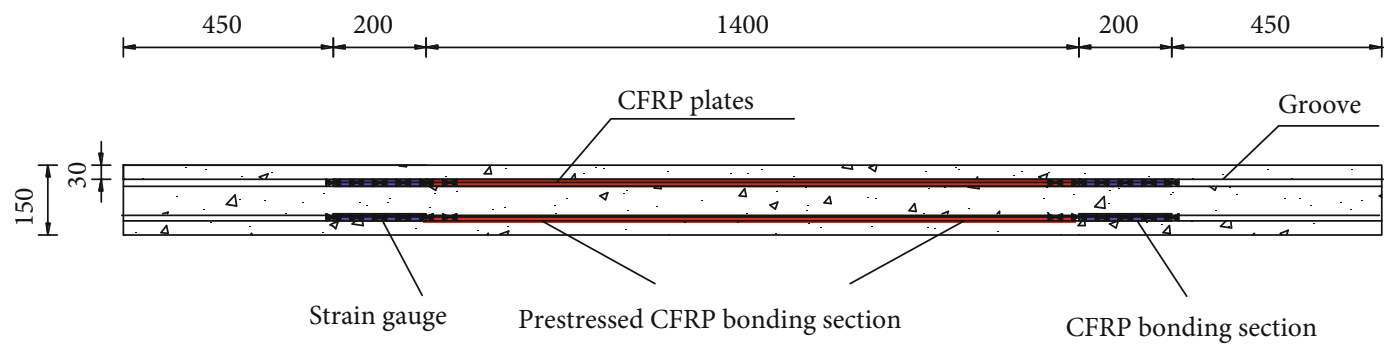

(b)

Figure 6: Test beam 1 details (unit: $\mathrm{mm}$ ).

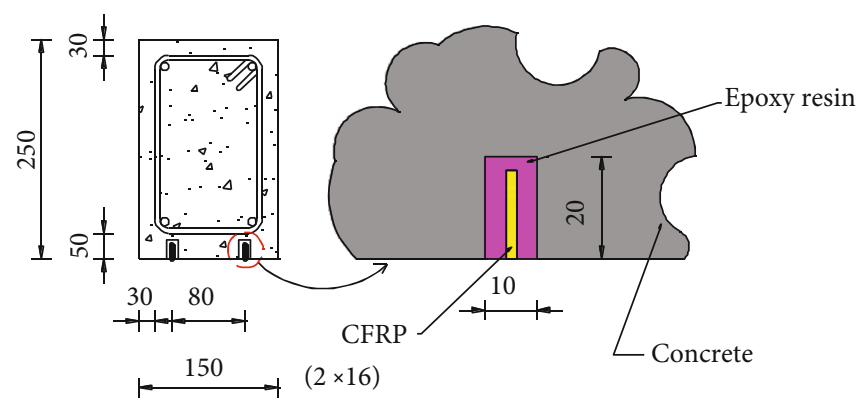

Figure 7: Cross-section details (unit: mm).

TABLE 1: Mixture proportions of the concrete specimens.

\begin{tabular}{lcccccc}
\hline Specimen designation & Cement $\left(\mathrm{kg} / \mathrm{m}^{3}\right)$ & Water $\left(\mathrm{kg} / \mathrm{m}^{3}\right)$ & Sand $\left(\mathrm{kg} / \mathrm{m}^{3}\right)$ & Stone $\left(\mathrm{kg} / \mathrm{m}^{3}\right)$ & Admixture $\left(\mathrm{kg} / \mathrm{m}^{3}\right)$ & $\mathrm{Nano}-\mathrm{CaCO}$ \\
\hline Beam1 & 372 & 175 & 815 & 996 & 7.4 & 7.44 \\
\hline
\end{tabular}

mixed in $3: 1$ proportion. The epoxy resin material at the $15^{\circ} \mathrm{C}$ for 7 days achieved the following properties. The tensile strength of epoxy resin is $24-27 \mathrm{MPa}$, the tensile modulus is 11.2 $\mathrm{GPa}$, and the shear strength is $14-17 \mathrm{MPa}$. The diameter of longitudinal distribution reinforcements in the specimen is $16 \mathrm{~mm}$. The yield strength is $400 \mathrm{MPa}$, the ultimate tensile strength is $540 \mathrm{MPa}$, and the elastic modulus is $201.9 \mathrm{GPa}$. The diameter of steel stirrups in the specimen is $8 \mathrm{~mm}$. The yield strength is $335 \mathrm{MPa}$, the ultimate tensile strength is $445 \mathrm{MPa}$, and the elastic modulus is $200 \mathrm{GPa}$. The protective layer thickness of longitudinal distribution reinforcement and steel stirrup is $30 \mathrm{~mm}$. In the research, the steel stirrups are arranged with a spacing of $100 \mathrm{~mm}$ along the length of the test specimen. In the experiment, SA and SNA were fixed on steel bars using steel wire. The SA and SNA are installed in the tension zone of the beam, as shown in Figure 6.
Figure 8 shows the preparation process of the test specimen. Before the concrete is poured, the SA and SNA are fixed at a predetermined position, and then, the concrete is poured into the mold to form test beam specimen. After 30 days of curing, a $10 \mathrm{~mm} \times 20 \mathrm{~mm}$ groove was fabricated at the bottom of the test specimen. The tension of the prestressed CFRP plate is completed on the tension test device, which mainly includes a tensioning pedestal, a load cell, an anchor, and a jack. The applied force is measured by a comprehensive tester and a load cell. The initial prestress applied was $900 \mathrm{MPa}$. The prestressed CFRP plate was embedded in the groove and bonded with epoxy resin. After curing for 7 days, the anchor end of the CFRP plate was cut, and prestress was applied to the strengthened beam by the bonding of the CFRP plate and the structural adhesive. 

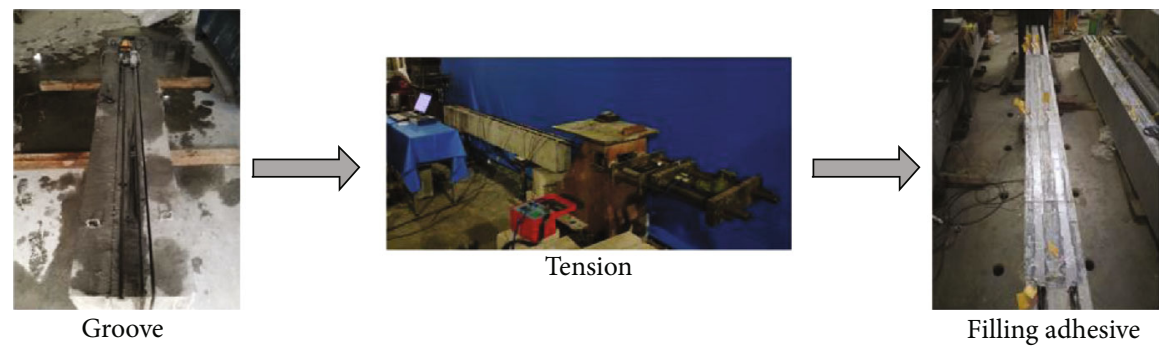

Figure 8: Beam specimen preparation.

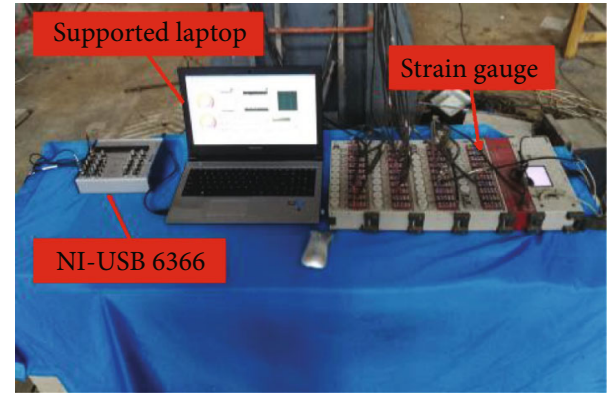

Figure 9: Experimental setup.

2.6. Experimental Procedures. The experimental equipment of the damage monitoring system used in this paper mainly include nanomaterial concrete beam, CFRP, SAs, SNAs, reaction frame, load cell, screw jack, steel pad, load distribution beam, concrete support piers, fixed support, sliding support, dial indicators, multifunctional strain gauge, data acquisition system (NI-USB 6366), and laptop with support software, as shown in Figures 9 and 10. The strain change of the CFRP plates during the loading process was measured using a multifunctional strain gauge. The measuring range of multifunctional strain gauge is $-640,000 \mu \varepsilon \sim+640,000 \mu \varepsilon$. The highest resolution is $0.1 \mu \varepsilon$. The sampling speed is fast, and it takes only 0.4 seconds to sample 1000 points of data. The deflection was measured by a dial indicator, the load was applied to the beam with a screw jack, and the load value was measured with a load cell. The data acquisition system NI-USB 6366 can be used for excitation and sampling simultaneously. In order to ensure the accuracy of the data, the data acquisition system NI-USB 6366 needs to be verified before the test. The data acquisition module was written using NI-LABVIEW software to support the data acquisition system NI-USB 6366. In this paper, the designed swept sine wave signal is used for excitation. The parameters of the swept sine wave signal are shown in Table 2. NI LABVIEW software is written to achieve data acquisition, storage, and filtering. The signal filtering is processed by a bandpass filter with a cut-off frequency of $50,000 \mathrm{~Hz}$ to $150,000 \mathrm{~Hz}$. Data analysis was performed using MATLAB software. The "db2" wavelet packet provided by MATLAB is selected in the process of wavelet packet analysis. The original signal measured by SA/SNA is decomposed into three layers of wavelet packets. Before the formal loading test, in order to eliminate the initial defect of the specimen and the normal operation of the instrument, the preload test is performed.
The formal loading of specimen starts from $0 \mathrm{kN}$ until complete failure. The data was collected in increments of $10 \mathrm{kN}$ for each load level in the test. During the loading process, data are collected once for each load level, and multiple measurements are taken at the same location. Meanwhile, strain data were collected and deflection changes were recorded. After each stage of loading, the specimen will have sufficient deformation time, and the data will be measured after deformation stability.

\section{Experimental Results}

3.1. Load Characteristics of the Specimens. During the loading process, initial cracks were formed in the CFRP tension end and bond end of the specimen at $20 \mathrm{kN}$ and $45 \mathrm{kN}$, respectively, and initial cracks were formed in the midspan at $40 \mathrm{kN}$. As the load continues to increase, the extent of crack growth increases. Finally, the protective layer debonding failure occurred from the CFRP-bonded end of the specimen to the middle of the span at the $105 \mathrm{kN}$ loading stage. It shows that the cracking load of the tension end is $20 \mathrm{kN}$, the cracking load of the bonding end is $45 \mathrm{kN}$, the cracking load of the midspan is $40 \mathrm{kN}$, and the ultimate load is $105 \mathrm{kN}$. Compared with the tensioned end, the cracking load of the bonded end is increased by $125 \%$, and the cracking load of the midspan is increased by $100 \%$. The failure characteristics of the specimen after the loading process are shown in Figure 11. It can be seen from Figure 11 that the concrete at the bottom of the specimen appears debonding failure when the tensile strength of concrete exceeds its tensile strength. During the loading process, the debonding cracks only appear in the strengthened zone of CFRP. The above analysis shows that the contact area between CFRP and concrete improves the stress distribution of the concrete and slows down the occurrence and propagation of the cracks. The properties of nanomaterial improve the service performance of the test specimen. The load deflection curve of the midspan in the specimen is shown in Figure 12. During the $40 \mathrm{kN}$ loading phase, the load deflection curve showed a slight change. When debonding failure occurs, the ultimate deflection of the specimen is $14.88 \mathrm{~mm}$. It can be seen from Figure 12 that the structure is generally in the elastic deformation stage. In fact, serious debonding damage has occurred between the CFRP plate and the concrete during the loading stage of $100 \mathrm{kN}$. Therefore, it is considered that the deflection of the specimen cannot provide an early warning of the interface debonding failure between the CFRP material and the concrete. Figure 13 shows the CFRP axial strain distribution 

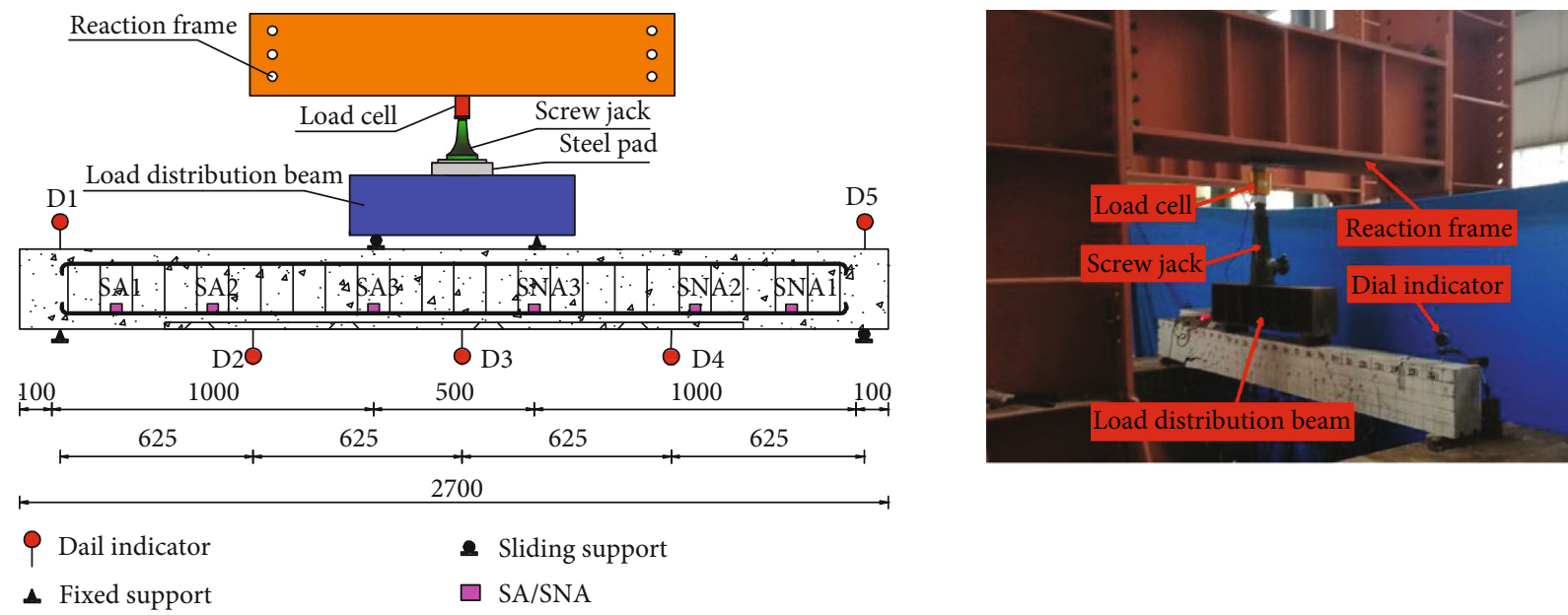

FIGURE 10: Specimen loading system.

TABle 2: Parameters of swept sine wave signal.

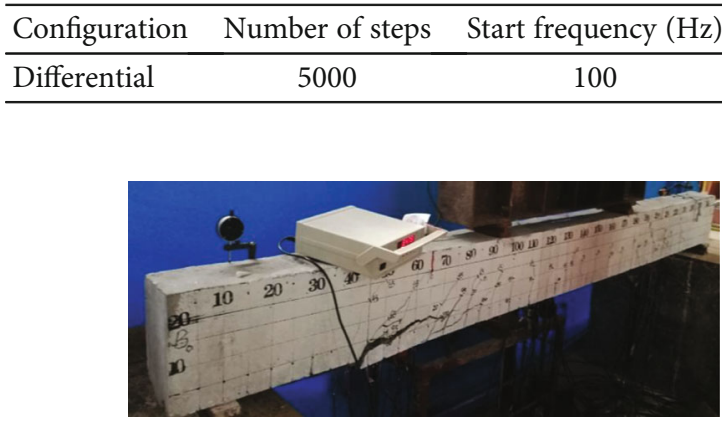

Figure 11: Failure photos of the specimen.

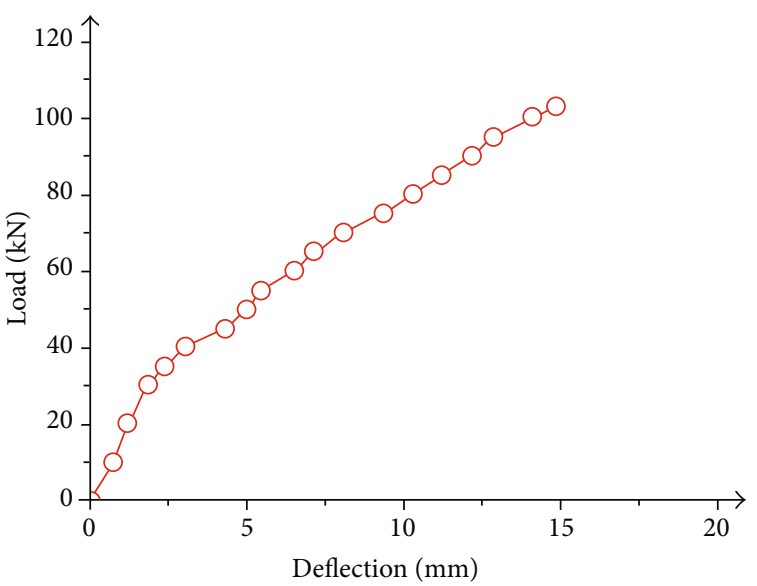

FIGURE 12: The load deflection curve.

curve of the test specimen. It can be seen from Figure 13 that the strain peak in the nonprestressed CFRP bonding section exhibits a tendency to move from the tension end to the bonding end with the increase of load. The strain of CFRP bond end was about $400 \mu \varepsilon$ during the

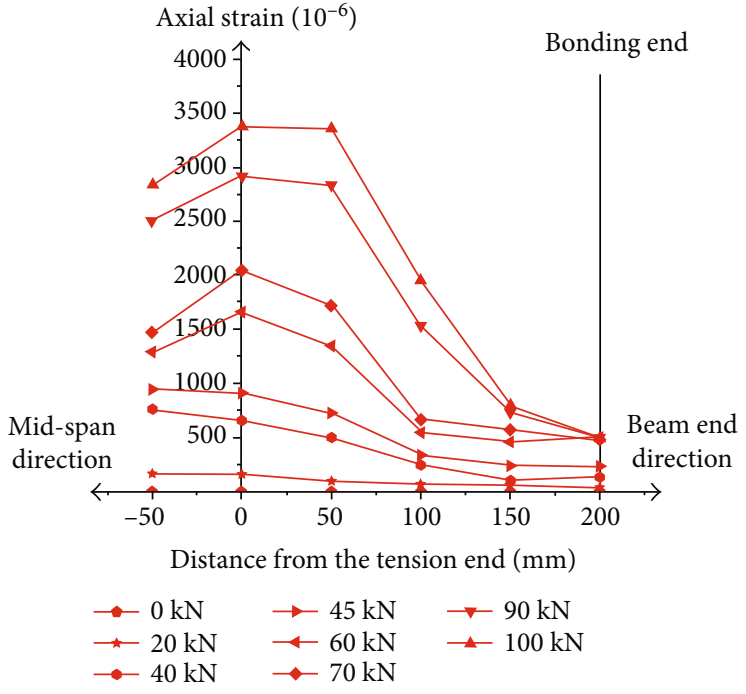

Figure 13: CFRP strain distribution

$100 \mathrm{kN}$ loading phase, indicating that the strain was fully transmitted within the nonprestressed CFRP bond section. The released tensile prestress is equivalent to an axial drawing force for the nonprestressed bonded section. It can be seen from Figure 13 that the strain data has a good linear relationship with the load during the loading process. In the stage of $100 \mathrm{kN}$ loading, the interface debonding phenomenon has occurred at the end of the CFRP plate, but the strain data has not changed obviously at this time. It is indicated that the strain analysis of the CFRP plate cannot monitor and warn the interface debonding failure between the CFRP plate and the concrete. 

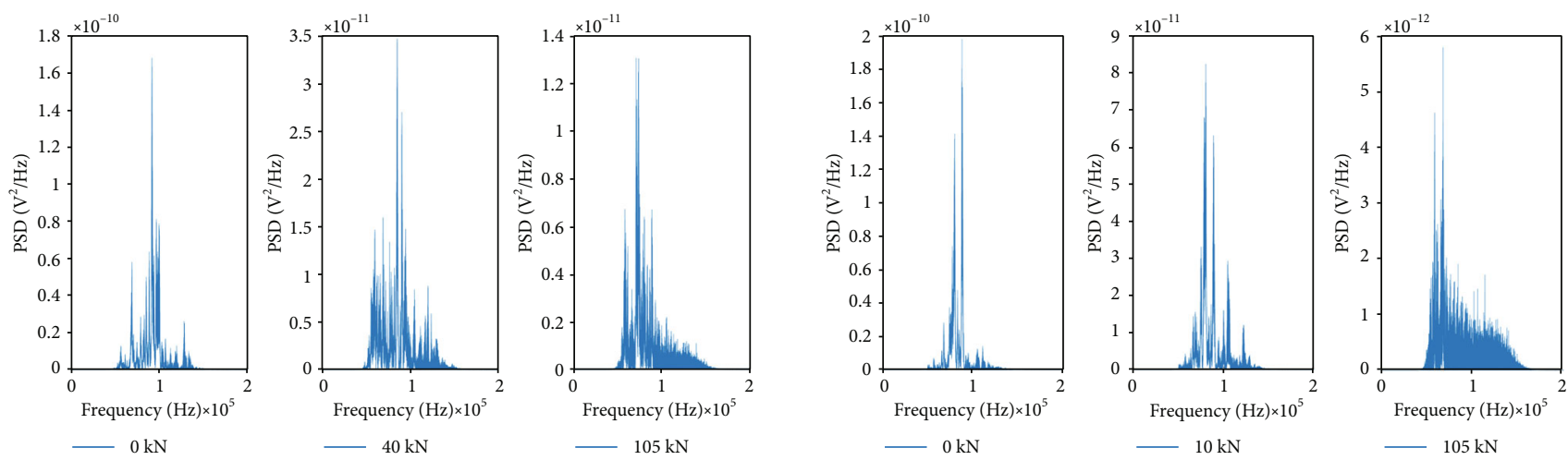

FIGURE 14: Frequency domain signal of SNA1 and SNA3 sensors.
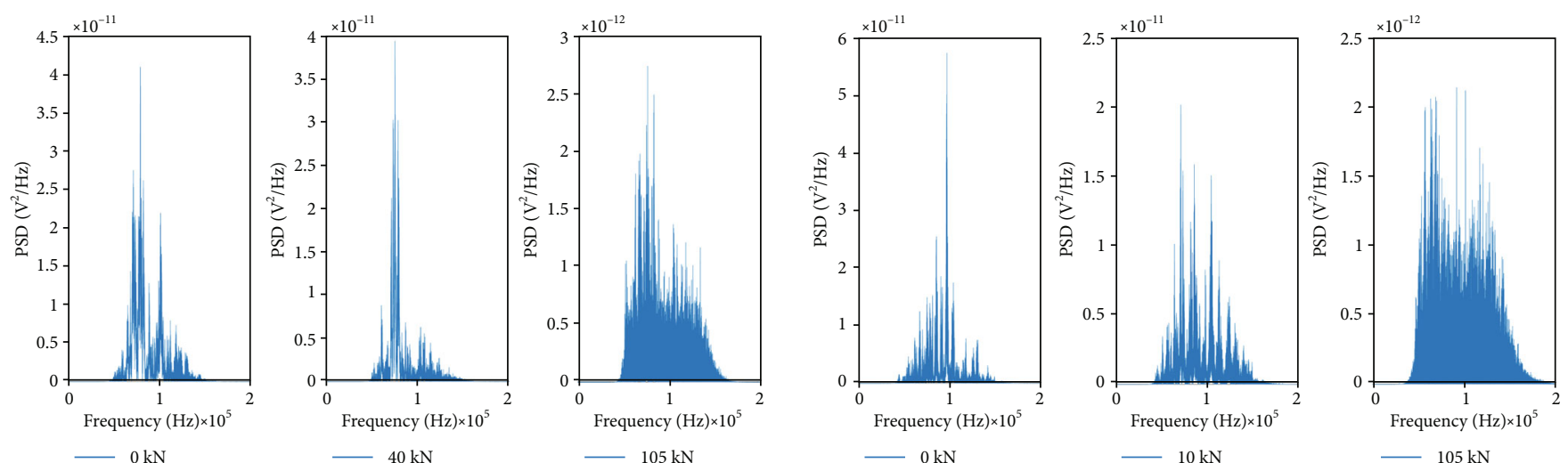

FIgURE 15: Frequency domain signal of SA1 and SA3 sensors.

3.2. Frequency Domain Analysis. The downward trend in power spectral density (PSD) energy can be more easily observed in the frequency domain than in the time domain signal. In order to reduce the space of this paper, three typical states (healthy state, initial debonding state, and failure state) of the SA/SNA sensor are given in frequency domain signal analysis. In the specimen of this experiment, the SA2 and SNA2 sensors were used as the actuator, and the other sensors were used as the receiver. The frequency domain signals received by SNA1 and SNA3 of specimen are shown in Figure 14, respectively. The frequency domain signals of SA1 and SA3 sensors in the specimen are shown in Figure 15, respectively. The results show that the initial debonding and failure states of the test specimen can be found by frequency domain analysis. The reason is that debonding cracks appear at the interface of the test specimen with the increase of the load, which will lead to the reflection and attenuation of the stress wave signal. On the other hand, the embedded SA-induced stress wave is sensitive to the debonding conditions of the interface. The reason is that the propagation of stress wave is enhanced by the addition of nano- $\mathrm{CaCO}_{3}$ into concrete. Nano- $\mathrm{CaCO}_{3}$ concrete becomes a good pipeline for wave propagation because of the nucleation and filling effect of nanomaterials. It can be seen from Figures 14 and 15 that the amplitudes of the sensors with nanomaterial are significantly larger than those without nanomaterial at $0 \mathrm{kN}$ loading stage. During the data acquisition process, the SNA actuator generates a swept sine wave signal, and the sensor of the received signal is highly sensitive to the debonding crack condition between CFRP and concrete. Therefore, the SNA transducers can reduce the energy loss of the propagation process. It shows that the sensors with nano- $\mathrm{CaCO}_{3}$ are more sensitive than the sensors without nano- $\mathrm{CaCO}_{3}$. The above analysis shows that the nucleation and filling effect of nano- $\mathrm{CaCO}_{3}$ reduces the interior porosity of the concrete, improves the strength of the structure, enhances the propagation of stress wave, and increases the amplitude of signal.

3.3. Wavelet Packet Analysis. In order to quantify the signal energy monitored during the loading process, the wavelet packet energy analysis method is used to calculate the degree of debonding damage. The energy distribution of the sensor during the loading process is shown in Figures 16 and 17. It can be seen from Figures 16 and 17 that the energy distribution of the sensor is mainly in frequency bands 1,2 , and 4 . The frequency band energy value of the sensors decreases with the increase of the applied load in the test specimens. A sharp decrease in frequency band energy indicates that debonding cracks occur during this loading phase. It can be seen in the energy distribution of the SNA1 sensor that an initial debonding crack occurs during the $40 \mathrm{kN}$ loading 

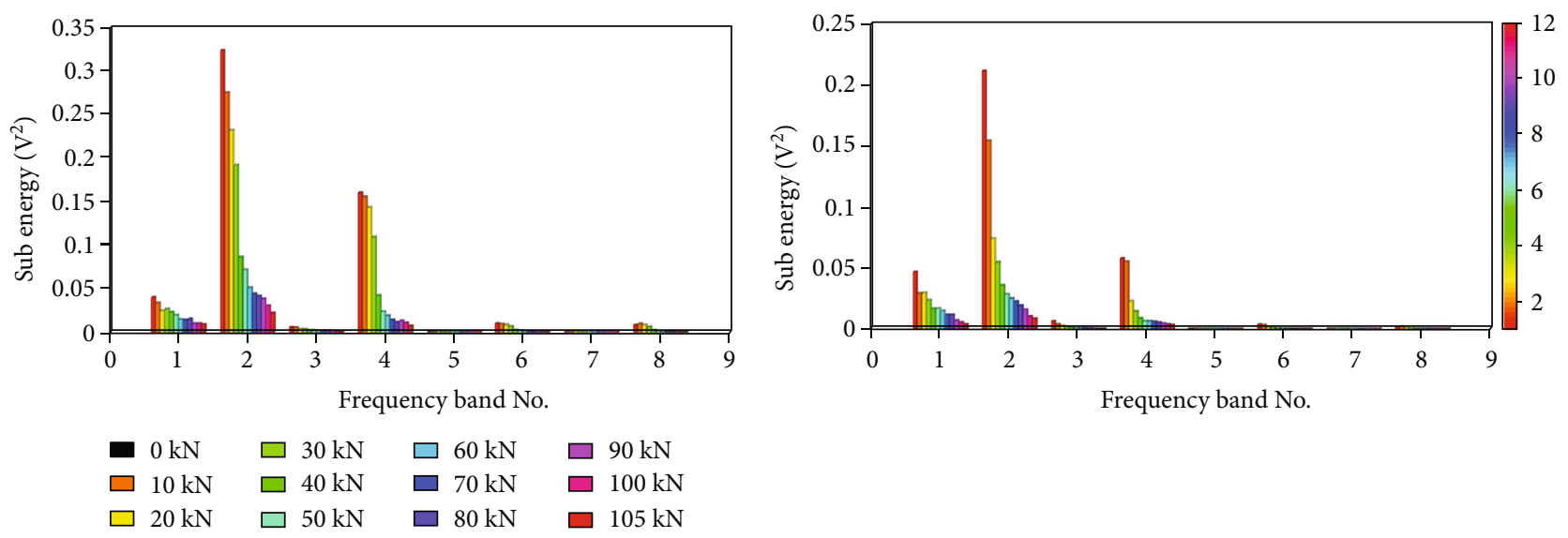

Figure 16: Energy distribution of SNA1 and SNA3 sensors.
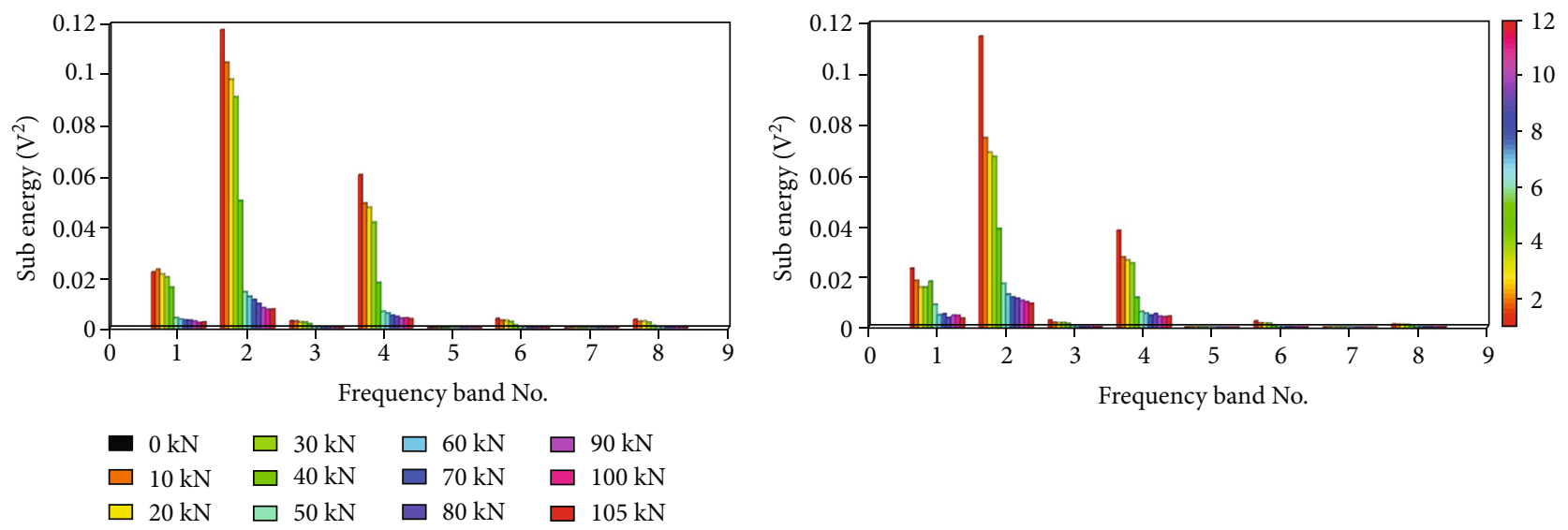

Figure 17: Energy distribution of SA1 and SA3 sensors.

phase. It can be seen in the energy distribution of the SNA3 sensor that an initial debonding crack occurs during the $10 \mathrm{kN}$ loading phase. New debonding cracks also appeared during the $20 \mathrm{kN}$ loading phase. Similarly, it can be seen in the energy distribution of the SA1 sensor that the initial debonding crack occurs in the $40 \mathrm{kN}$ loading phase. It can be seen in the energy distribution of the SA3 sensor that an initial debonding crack occurs during the $10 \mathrm{kN}$ loading phase. Debonding cracks cause attenuation of energy in each frequency band. Wavelet packet distribution energy analysis shows that the tension end region cracks earlier than the bond end region with the increase of load. The reason is that stress concentration at the end of CFRP results in debonding damage at the beginning of loading, which also proves the starting point of structural debonding damage. The energy value received by the SNA sensor is higher than the energy value received by the SA sensor. It is shown that sensors with nanomaterial have been improved for energy dissipation.

Similarly, the wavelet packet energy can also be analyzed intuitively. The wavelet packet energy of the specimen is shown in Figures 18 and 19. It can be seen from Figures 18 and 19 that the value of the wavelet packet energy decreases as the loading progresses. At the initial stage of loading, it is found that the amplitude and energy of the received signal are decreasing significantly, and the sensors at the prestressed bond end decrease faster than those at other places, which proves the starting point of structural damage. As the load increases, cracks are generated and expanded inside the beam, which weakens the propagation of the stress wave and reduces the amplitude and energy of the received signal. When debonding failure is caused by crack development, the amplitude and energy of the received signal become stable. Therefore, the wavelet packet energy analysis method can visually represent the initial debonding crack, and the decreasing trend of energy shows the damage degree of the debonding crack. The energy values received from the SNA and SA sensors found that the SNA sensor energy value was greater than SA. The SNA1 sensor energy value is greater than SNA3. It shows that the sensor with nanomaterial is more sensitive than SA. It is found that debonding damage occurs in $40 \mathrm{kN}$ and $10 \mathrm{kN}$ loading stages from the energy values received by SNA1 and SNA3 sensors. It is found that debonding damage occurs in $40 \mathrm{kN}$ and $10 \mathrm{kN}$ loading stages from the energy values received by SA1 and SA3 sensors. By comparing the wavelet packet energy, it can be seen that the wavelet packet energy of SNA3 and SA3 decreases faster with 

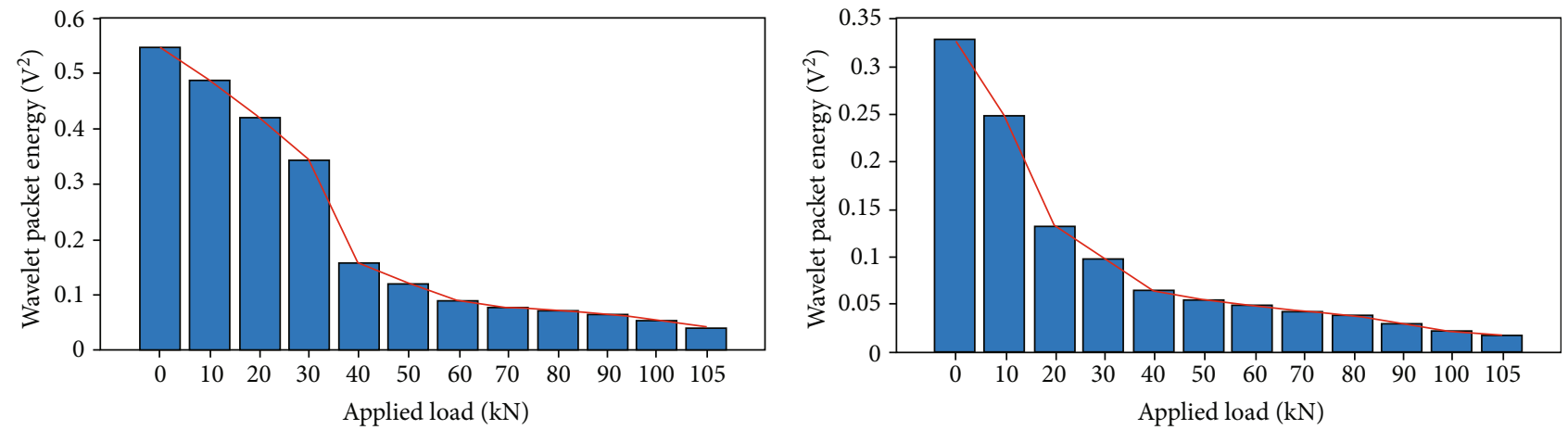

Figure 18: Wavelet packet energy of SNA1 and SNA3 sensors.
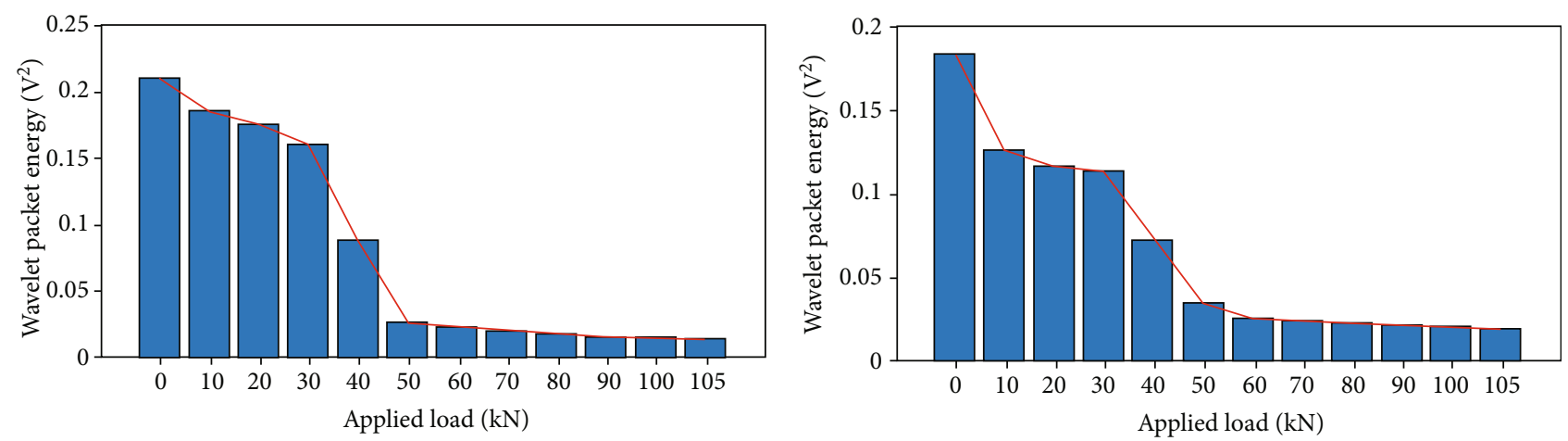

FIgURE 19: Wavelet packet energy of SA1 and SA3 sensors.

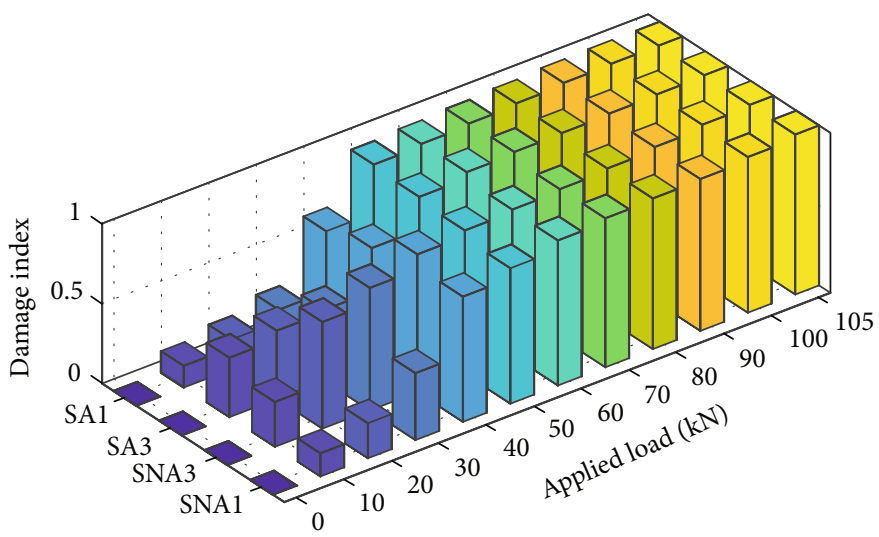

Figure 20: Normalized RMSD-based damage index.

the increase of applied load. It is indicated that the tensioned end region cracks earlier than the bonded end region due to the influence of the stress change.

In addition, the normalized RMSD-based damage index was applied to evaluate the damage condition quantitatively; the result is shown in Figure 20, in which the index is 0 in the case of $0 \mathrm{kN}$ (without debonding), while the index is 1 in the case of beam load at $105 \mathrm{kN}$ (completely debonding). Figure 20 shows the damage index of the SA/SNA sensor in the beam during the applied load process. It can be clearly seen from Figure 20 that the value of the damage index increases with the increase of the loading process, which reflects the severity of the debonding damage. The obvious increasing values of each sensor in the beam can be found in the figure, indicating that an initial debonding crack occurred at the interface. It can be seen from the damage index distribution of the SNA1 sensor that the initial debonding crack appeared during the $40 \mathrm{kN}$ loading stage. From the damage index distribution of the SNA3 sensor, it can be seen that an initial debonding crack appeared during the $10 \mathrm{kN}$ loading phase. Similarly, it can be seen from the damage index distribution of the SA1 sensor that the initial 
debonding crack occurred during the loading stage of $40 \mathrm{kN}$. It can be seen in the damage index distribution of the SA3 sensor that an initial debonding crack appeared during the $10 \mathrm{kN}$ loading phase. At the initial stage of loading, it is found that the damage index of the received signal was increasing significantly, and the sensors at the prestressed bond end increase faster than those at other places, which proves the starting point of structural damage. As the load increases, cracks are generated and expanded inside the beam, which weakens the propagation of the stress wave and increases the damage index of the received signal. When debonding failure is caused by crack development, the damage index of the received signal becomes stable. Wavelet packet damage index has the ability to detect debonding crack initiation. After the occurrence of debonding cracks, the value of damage index increasing continuously monitors the development of debonding cracks. Compared with the wavelet packet energy, the severity of the damage can be seen more easily from the damage index. The above analysis shows that the damage index can well reflect the development trend of interface debonding damage. The initial and complete debonding stages can be successfully reflected in the damage index. Therefore, a conclusion can be drawn that the proposed damage index can be successfully used to evaluate the severity of debonding damage.

\section{Conclusions}

In this paper, an active sensing approach is proposed to monitor the interfacial debonding performance of the nanomaterial concrete beam with NSM prestressed CFRP plates. The properties of nanomaterial improve the service performance of the test specimen. The experimental study on the prestressed CFRP-SNCB interfacial debonding performance was conducted by using the wavelet packet theory based on SA/SNA-induced stress wave. Based on the experimental results, the following conclusions can be drawn:

(1) The analysis results show that the nucleation and filling effect of nano- $\mathrm{CaCO}_{3}$ reduces the interior porosity of the concrete, improves the strength of the structure, enhances the propagation of stress wave, and increases the amplitude of signal. Nano- $\mathrm{CaCO}_{3}$ concrete becomes a good pipeline for wave propagation. The embedded SA/SNA-induced stress wave is sensitive to the debonding conditions of the interface. The sensors with nano- $\mathrm{CaCO}_{3}$ are more sensitive than the sensors without nano- $\mathrm{CaCO}_{3}$

(2) Due to the influence of stress change, the debonding cracks mainly appear in the strengthened area of CFRP during the loading process. The contact area between the CFRP and the concrete improves the stress distribution of the concrete, slows down the occurrence and propagation of the cracks, and improves the service performance of the test specimens. The tension end region cracks earlier than the bond end region with the increase of load. Stress concentration at the end of CFRP results in debonding damage at the beginning of loading
(3) The frequency domain amplitude and wavelet packet energy of the signal received by the sensor with nanomaterial are higher than that of the signal received by the sensor without nanomaterial. The frequency domain amplitudes and wavelet packet energies of the signal received by SA/SNA sensors decrease when the debonding crack-induced damage occurs. The sensor at the prestressed bond end decreases faster than those at other places, which proves the starting point of structural damage

(4) The experimental results show that it is feasible to use the active sensing approach based on SAs/SNAs to monitor the occurrence and development of debonding cracks for the nanomaterial concrete beam with NSM prestressed CFRP plates in real time. From the analysis of deflection and strain, it is impossible to make an effective prediction of the degree of damage. The comparative analysis shows that the proposed active sensing approach has obvious advantages compared with the traditional measurement method

\section{Data Availability}

The data used to support the findings of this study are available from the corresponding author upon request.

\section{Conflicts of Interest}

The authors declare that there is no conflict of interest regarding the publication of this paper.

\section{Acknowledgments}

The authors are grateful for the partial financial support received from the Major State Basic Research Development Program of China (973 Program, grant number 2015CB057704), the National Nature Science Foundation of China (Grant No. 51378081), the Natural Science Foundation of Hunan Province (Grant No. 2019JJ40313), and the Hunan Provincial Innovation Foundation for Postgraduate (CX20190651).

\section{References}

[1] L. Xia and Y. Zheng, "Deep embedment (DE) FRP shear strengthening of concrete bridge slabs under loads close to supports," Applied Sciences, vol. 8, no. 5, p. 721, 2018.

[2] J. Kim, "Reinforced concrete with FRP bars: mechanics and design," Proceedings of the Institution of Civil Engineers Civil Engineering, vol. 168, no. 4, pp. 154-154, 2015.

[3] F. Sanchez and K. Sobolev, "Nanotechnology in concrete - a review," Construction and Building Materials, vol. 24, no. 11, pp. 2060-2071, 2010.

[4] V. S. Kuntal, M. Chellapandian, and S. S. Prakash, "Efficient near surface mounted CFRP shear strengthening of high strength prestressed concrete beams - an experimental study," Composite Structures, vol. 180, pp. 16-28, 2017. 
[5] W. Li, S. Fan, S. C. M. Ho, J. Wu, and G. Song, "Interfacial debonding detection in fiber-reinforced polymer rebar-reinforced concrete using electro-mechanical impedance technique," Structural Health Monitoring, vol. 17, no. 3, pp. 461-471, 2018.

[6] X. Yin, G. Song, and Y. Liu, "Vibration suppression of wind/traffic/bridge coupled system using multiple pounding tuned mass dampers (MPTMD)," Sensors, vol. 19, no. 5, p. 1133, 2019.

[7] J. Peng, S. Hu, J. Zhang, C. S. Cai, and L. Y. Li, "Influence of cracks on chloride diffusivity in concrete: a five-phase mesoscale model approach," Construction and Building Materials, vol. 197, pp. 587-596, 2019.

[8] X. Yin, Y. Liu, G. Song, and Y. L. Mo, "Suppression of bridge vibration induced by moving vehicles using pounding tuned mass dampers," Journal of Bridge Engineering, vol. 23, no. 7, article 04018047, 2018.

[9] F. U. A. Shaikh and S. W. M. Supit, "Mechanical and durability properties of high volume fly ash (HVFA) concrete containing calcium carbonate $\left(\mathrm{CaCO}_{3}\right)$ nanoparticles," Construction and Building Materials, vol. 70, pp. 309-321, 2014.

[10] S. W. M. Supit and F. U. A. Shaikh, "Effect of nano- $\mathrm{CaCO}_{3}$ on compressive strength development of high volume fly ash mortars and concretes," Journal of Advanced Concrete Technology, vol. 12, no. 6, pp. 178-186, 2014.

[11] Z. Wu, C. Shi, P. Gao, D. Wang, and Z. Cao, "Effects of deicing salts on the scaling resistance of concrete," Journal of Materials in Civil Engineering, vol. 27, no. 5, article 04014160, 2015.

[12] W. Kuang, Z. Liu, H. Yu et al., "Investigation of internal concentration polarization reduction in forward osmosis membrane using nano-CaCO3 particles as sacrificial component," Journal of Membrane Science, vol. 497, pp. 485-493, 2016.

[13] K. Xu, C. Ren, Q. Deng, Q. Jin, and X. Chen, "Real-time monitoring of bond slip between GFRP bar and concrete structure using piezoceramic transducer-enabled active sensing," Sensors, vol. 18, no. 8, p. 2653, 2018.

[14] D. Goyal and B. S. Pabla, "The vibration monitoring methods and signal processing techniques for structural health monitoring: a review," Archives of Computational Methods in Engineering, vol. 23, no. 4, pp. 585-594, 2016.

[15] G. Song, C. Wang, and B. Wang, "Structural health monitoring (SHM) of civil structures," Applied Sciences, vol. 7, no. 8, p. 789, 2017.

[16] J. Wu, Q. Kong, I. Lim, and G. Song, "Feasibility study of interlayer slide monitoring using postembedded piezoceramic smart aggregates," Journal of Sensors, vol. 2018, Article ID 1953528, 10 pages, 2018.

[17] Z. Zhao, P. Chen, E. Zhang, and G. Lu, "Health monitoring of bolt looseness in timber structures using PZT-enabled timereversal method," Journal of Sensors, vol. 2019, Article ID 2801638, 8 pages, 2019.

[18] T. Jiang, Y. Hong, J. Zheng, L. Wang, and H. Gu, "Crack detection of FRP-reinforced concrete beam using embedded piezoceramic smart aggregates," Sensors, vol. 19, no. 9, p. 1979, 2019.

[19] Y. Liu, M. Zhang, X. Yin, C. Hei, and L. Wang, "Interface debonding detection of precast segmental concrete beams (PSCBs) using piezoceramic transducer-based active sensing approach," Mathematical Problems in Engineering, vol. 2019, Article ID 8725021, 11 pages, 2019.
[20] W. Yan, J. Zhou, H. Liu, R. Chen, Y. Zhang, and Y. Wei, "Formation of goethite and magnetite rust via reaction with $\mathrm{Fe}(\mathrm{II})$," Journal of the Electrochemical Society, vol. 163, no. 6, pp. C289-C295, 2016.

[21] S. Uthaman, R. P. George, V. Vishwakarma, M. Harilal, and J. Philip, "Enhanced seawater corrosion resistance of reinforcement in nanophase modified fly ash concrete," Construction and Building Materials, vol. 221, pp. 232-243, 2019.

[22] Y. Liu, K. Liu, H. Dong et al., "Acetylcholinesterase biosensor for carbaryl detection based on nano-porous pseudo carbon paste electrode," Nanoscience and Nanotechnology Letters, vol. 8, no. 9, pp. 785-790, 2016.

[23] H. Taherkhani and M. Tajdini, "Comparing the effects of nano-silica and hydrated lime on the properties of asphalt concrete," Construction and Building Materials, vol. 218, pp. 308315, 2019.

[24] A. Wu, S. He, Y. Ren, N. Wang, S. Ho, and G. Song, "Design of a new stress wave-based pulse position modulation (PPM) communication system with piezoceramic transducers," Sensors, vol. 19, no. 3, p. 558, 2019.

[25] T. Jiang, Q. Kong, Z. Peng et al., "Monitoring of corrosioninduced degradation in prestressed concrete structure using embedded piezoceramic-based transducers," IEEE Sensors Journal, vol. 17, no. 18, pp. 5823-5830, 2017.

[26] B. Xu, T. Zhang, G. Song, and H. Gu, "Active interface debonding detection of a concrete-filled steel tube with piezoelectric technologies using wavelet packet analysis," Mechanical Systems and Signal Processing, vol. 36, no. 1, pp. 7-17, 2013.

[27] L. Zeng, S. M. Parvasi, Q. Kong et al., "Bond slip detection of concrete-encased composite structure using shear wave based active sensing approach," Smart Materials and Structures, vol. 24, no. 12, article 125026, 2015.

[28] Y. Wang, X. Li, J. Li, Q. Wang, B. Xu, and J. Deng, “Debonding damage detection of the CFRP-concrete interface based on piezoelectric ceramics by the wave-based method," Construction and Building Materials, vol. 210, pp. 514-524, 2019.

[29] T. Jiang, B. He, Y. Zhang, and L. Wang, "Detecting of the longitudinal grouting quality in prestressed curved tendon duct using piezoceramic transducers," Sensors, vol. 20, no. 4, p. 1212, 2020.

[30] B. Xu, B. Li, and G. Song, "Active debonding detection for large rectangular CFSTs based on wavelet packet energy spectrum with piezoceramics," Journal of Structural Engineering, vol. 139, no. 9, pp. 1435-1443, 2013.

[31] T. Jiang, Q. Kong, D. Patil, Z. Luo, L. Huo, and G. Song, "Detection of debonding between fiber reinforced polymer bar and concrete structure using piezoceramic transducers and wavelet packet analysis," IEEE Sensors Journal, vol. 17, no. 7, pp. 1992-1998, 2017.

[32] L. Huo, D. Chen, Y. Liang, H. Li, X. Feng, and G. Song, "Impedance based bolt pre-load monitoring using piezoceramic smart washer," Smart Materials and Structures, vol. 26, no. 5, article 057004, 2017.

[33] Y. Liu, M. Zhang, X. Yin, Z. Huang, and L. Wang, "Debonding detection of reinforced concrete (RC) beam with near-surface mounted (NSM) pre-stressed carbon fiber reinforced polymer (CFRP) plates using embedded piezoceramic smart aggregates (SAs)," Applied Sciences, vol. 10, no. 1, p. 50, 2020. 